\title{
Faraday and the funding of science
}

In his Dimbleby Lecture, which was shown on British television on 10 April, Sir George Porter argued for the value of 'pure' research and took Michael Faraday's innovative work on electromagnetic induction as an exemplary case. The British prime minister,
Mrs Margaret Thatcher, also holds Faraday dear. Here Geoffrey Cantor questions whether Mrs Thatcher has the right hero, while overleaf Tony Gardner-Medwin provides a sceptics' guide to the worth of curiosity-based research.

\section{The scientist and his values}

\section{Geoffrey Cantor}

IN HIS address, Sir George Porter chastised the British government for its myopic pursuit of affluence and its failure to recognize the crucial role of scientific research. He argued that scientific research - particularly pure research - is essential for the long-term success of a nation's technology, and thus of its economy, and that it must not be jeopardized by a preoccupation with goals set solely by short-term economic considerations.

Sir George began with several historical examples and quotations taken from leading British scientists of the early nineteenth century - David Brewster, Charles Babbage and, most prominently, Michael Faraday. Faraday, claimed Sir George, had been engaged in rather fruitless and time-consuming experiments in the late $1820 \mathrm{~s}$, at the behest of a committee of the Royal Society. These were aimed at improving optical glass and its means of manufacture. Exasperated by this work, Faraday relinquished it in July 1831 in order to pursue a line of pure research which had been on his mind for some time. A mere two months later this research reached fruition with his momentous discovery of electromagnetic induction. As we know, this discovery has been crucial for a wide range of technologies of great economic importance.

Sir George is not alone in invoking the name of Faraday. Several months ago the Prime Minister was interviewed on the television programme Favourite Things, and was asked to name her historical hero. Surprisingly, she did not choose a politician but a scientist. Nor did she choose Newton, despite his association with Grantham, her place of birth. Instead she named Faraday, and admitted that she had inoved a bust of her hero into Number 10 Downing Street.

Yet Mrs Thatcher's Faraday is not the same Faraday offered to us by Sir George. She views Faraday as a genius who succeeded by virtue of his strength of character. Her Faraday is a Smilesian figure who transcended his humble background to become the most successful scientist of his generation. She particularly stressed that he succeeded with only a rudimentary education and without attending university. Moreover, she acknowledged the technological importance of Faraday's work but did not see him as having to choose between performing experiments on optical glass and seeking the laws of electromagnetism.

Sir George and Mrs Thatcher have thus employed images of Faraday for their own purposes. In this they are not original. Both during the latter half of his life and especially since his death in 1867 images of Faraday have been prominent and potent. However, those images have been contradictory and used for a variety of purposes. Three examples will suffice.

One image is encapsulated in the title of John Tyndall's Faraday as a Discoverer (1868). Faraday's success at scientific discovery has often been attributed to his (presumed) use of the inductive, experimental method. Thus this image has been deployed to make a methodological point.

Again, Faraday has often been seen as morally upright and Victorians frequently praised him for his humility, honesty and virtue. Indeed his attractive personality and moral virtues have been used to account for his success in science. Thus the Good has been linked with Truth.

A third image relates to his success as a science lecturer. This image has recently been reinforced by the Royal Society's concern to improve the public understanding of science. A new prize has therefore been instituted to reward those who make notable contributions to this area: the Faraday Prize.

In their uses of Faraday, Sir George and Mrs Thatcher stand in a long tradition and both have drawn on the Victorian image bank. Would Faraday himself have endorsed either of them? He certainly recognized the importance of the human spirit but he would not have seen his life in terms of worldly success. He was a member of a small Christian sect, known as the Sandemanians, who sought to live their lives according to the Bible and in imitation of Christ. Worldly success was not on their agenda and Faraday rejected all civil honours from Britain; he believed that they were tarnished by association with party politics and were not awarded for merit. He remained plain Mr Faraday and a servant of the Royal Institution, eschewing power and personal fortune.

It has sometimes been claimed that Faraday was a Tory, but although some of his attitudes were distinctly conservative, he strove to remain outside (if not above) party politics. This stance was shared by other Sandemanians who also insisted that the Bible required them to behave as loyal, law-abiding citizens. Thus out of a sense of duty Faraday frequently engaged in projects defined by the government and its agencies - for example he spent much time trying to improve lighthouse illuminants for Trinity House and he also experimented with different stone preservatives for use on the Houses of Parliament. Likewise, as Sir George pointed out, he felt duty-bound to enhance the Royal Institution and its finances.

Yet it is hard to believe that this loyal citizen would have supported Mrs Thatcher's policy towards science. He believed that, as part of God's providence, the laws of nature were fashioned to improve our lot. Science should be used for the good of mankind - he instanced such socially important science-based developments as the steam engine and the telegraph - but he was deeply opposed to the spirit of capitalism and the cult of affluence. Thus while knowledge of nature (pure science) should be used to assist mankind, it should not be exploited by those intent on lining their own pockets. The scientist and engineer deserved moderate rewards from applying their skills: for Faraday, however, they should not become rich through science, or else science would be corrupted.

Faraday would have viewed today's entrepreneurs and financial speculators as highly immoral. For him, as for other Sandemanians, the crucial text was Matthew 6:19 — "Lay not up for yourselves treasures upon earth". He would also have rejected the views Mrs Thatcher expressed recently before the General Assembly of the Church of Scotland. Faraday actively practised Biblical precepts: he prayed with the poor members of the Sandemanian community, loved them and supported them both spiritually and materially. On these points, at least, Mrs Thatcher has the wrong hero.

Geoffrey Cantor is Gifford Fellow in the Department of Modern History, University of Glasgow, Glasgow GI2 8QQ, UK. 